\title{
Jürgen Golte: el último viaje
}

\section{Melissa Golte Adams}

(iD) https://orcid.org/0000-0002-1829-1542

mekigol@gmail.com

Me siento frente a una hoja en blanco y me pregunto cómo construir un texto que lo represente. Debo confesar que he dejado la tarea múltiples veces de lado: hacerle justicia a una vida tan polifacética e interesante con palabras es, sin lugar a duda, un reto difícil.

Jürgen Golte nació en Danzig (actual Polonia) en 1943, cuando esta zona aún estaba anexada a Alemania. Su familia tuvo que viajar hasta ahí en esa época debido a la Segunda Guerra Mundial, que estaba pronta a terminar. Los tiempos de posguerra en un país vencido proporcionaron a él, a sus tres hermanas y a su hermano mayor una niñez en la que, a la par de ir a la escuela, se vieron en la necesidad de apoyar a sus padres en la granja en la cual vivían.

El contexto de gran escasez hizo que aprendiesen a aprovechar la naturaleza en su entorno para subsistir. Recuerdo que él sabía cosechar las hojas de las ortigas sin que le picasen las manos. Mencionaba que era común que comiesen sopa de ortigas y papas que cosechaban ahí mismo. No eran recuerdos amargos cuando los contaba. Tuvo una niñez interesante, en la que descubrió su afición por la lectura de ficción y de la historia. Su madre — mi abuela, más conocida como «la Grossmama»— tenía una vena artística y los invitaba a fabricarse sus propios juguetes, a leer y a tener gusto por la cocina.

Desde niño tuvo una gran afición por viajar y conocer, por lo que recorrió largas rutas con sus hermanos en bicicleta. Una de sus travesías ciclistas que me contó reiteradas veces fue aquella en la que llegó con su hermano Winfried a la Dordoña en Francia, donde lograron ver las pinturas rupestres de Lascaux. Una anécdota curiosa de ese viaje fue que debieron buscar a un señor en su casa para pedirle las llaves para ingresar al sitio. Ahí me lo imagino, a los dieciséis o diecisiete años, mirando esas pinturas con más de quince mil años de antigüedad,

Este artículo se basa en un homenaje y recuerdo leído en el conversatorio «El mundo andino y la obra de Jürgen Golte» organizado por el Centro Bartolomé de las Casas y el Instituto de Estudios Peruanos llevado a cabo el cinco de noviembre de 2021. 


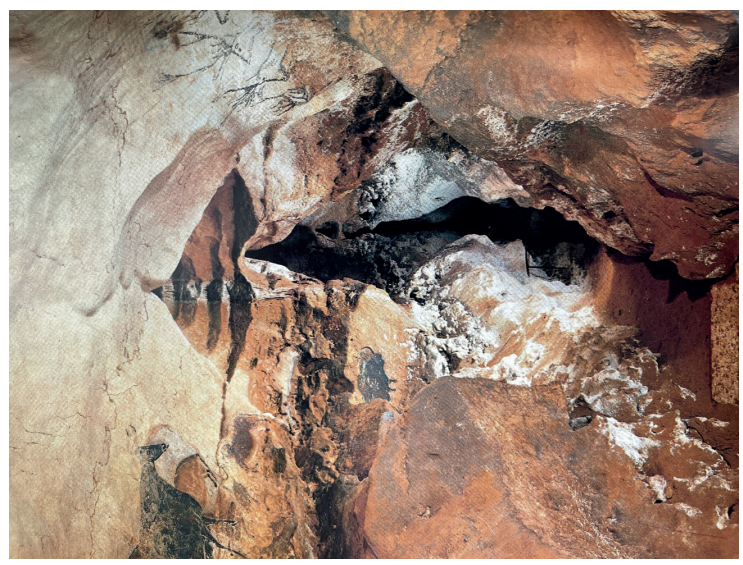

Cueva Lascaux. (Imagen del libro Lascaux Höhle der Eiszeit. Catálogo de exposición sobre estas pinturas rupestres, editorial Phillip von Zabern, 1982).

ya pensándose como parte de la historia que nos trasciende como individuos. Además, seguramente empezando a conocer la amplia diversidad de maneras de ver la vida y el cosmos a través del espacio y el tiempo.

Estoy segura de que este momento lo marcó, por la ilusión que siempre reflejaban sus ojos al hablar de las pinturas rupestres. $Y$ tal vez eso hizo que recibiera con tanto interés la necesidad de la Humanidad de seguir expresándose a través de dibujos en las paredes. Así, cuando de niña pintaba las paredes de la casa, en lugar de amonestaciones o reprimendas, escuchaba sobre Lascaux, Altamira, la puerta de Babilonia, y también de los Moche y sus magníficos frisos que aún pueden visitarse en la costa norte.

En retrospectiva debo decir que el saberse parte de una historia tan vasta y antigua lo hacía tener una visión abierta hacia cosas que a veces vemos como nuevas, pero son tan antiguas como el propio proceso de evolución humana. Así, por ejemplo, la travesura de hacerme un tatuaje se convertía en una conversación larga sobre la Dama de Cao del valle de Chicama o de la cultura de los maori de Nueva Zelanda. O un día «simple» en el jardín era una exploración botánica y un paseo «rutinario» al museo devenía un genuino y emocionante viaje iconográfico en el tiempo.

Otro viaje que en definitiva marcó su vida fue aquel que lo trajo de joven a la América del Sur. Después de trabajar en su país en las cosas más diversas, estudiar matemática e incursionar en el mundo de la «Americanística antigua», se embarcó desde Lisboa a Río de Janeiro. Me resulta curioso preguntarme si en el barco surcando las olas del Atlántico habrá llegado a imaginarse remotamente que aquí 
se embarcaría en un viaje más largo. Un viaje por las rutas de la antropología, de la paternidad, y que se volvería un profesor muy querido por sus «alumnitas y alumnitos» (como los llamaba a veces de cariño).

Desembarcó en Brasil, pasó a Bolivia y luego llegó al Perú. Ese camino no estuvo exento de vivencias singulares: mencionó incluso haber convivido y trabajado con una familia de contrabandistas. El idioma latín, que había aprendido de niño en su colegio en Alemania, le facilitó desplegarse en el aprendizaje de los idiomas que iba encontrando. A su vez, la curiosa coincidencia entre algunos factores del alemán con el quechua facilitó también su comprensión de este antiguo idioma andino. Su niñez, en la que practicó y subsistió de la cosecha y recolección, hizo que se sintiese muy a gusto en la región andina, que le resultaba nueva, pero a su vez extrañamente familiar. Así, él iba haciendo camino al andar. Llegó a la capital del Perú y encontró un hogar en la Universidad Nacional Mayor de San Marcos, donde estudió Antropología y Arqueología.

Su colega y amigo Jaime Urrutia escribió:

Entusiastas jovenzuelos dispuestos a devorar el conocimiento, ocupábamos las pequeñas aulas que habían sido diseñadas para residencia de estudiantes de provincias ingresantes a la Universidad de San Marcos, pero perdieron esa función originaria pues allí funcionaba la escuela de Antropología. En el vestíbulo de entrada del pabellón de la residencia, era ya un personaje extraño, aquel teutón, alto y desgarbado, que descendía del dormitorio que ocupaba cual estudiante migrante sin recursos, para acudir a las clases programadas. Esa es la primera imagen que guardo de Jürgen Golte. Meses después, embarcados por José Matos Mar a través del IEP, nos tocó a todos los compañeros integrar los equipos de antropólogos en ciernes que transitaron por las comunidades del valle de Chancay. Jürgen fue designado como maestroguía de nuestro equipo, en Pacaraos, y puedo afirmar que allí nació no solo nuestra amistad sino también la admiración que muchos tuvimos por quien nos corregía, sugería, afirmaba lo que íbamos adelantando en nuestras observaciones (homenaje postmortem de Jaime Urrutia a Jürgen Golte titulado «In memoriam Jürgen Golte Rohde: desaliñado, hosco, lúcido y solidario»).

Carlos Iván Degregori, su amigo y colega, leyó un apasionante discurso cuando se entregó a mi papá el Doctorado Honoris Causa. En un extracto de este discurso nos acercamos aún más a esta etapa de su vida:

Apenas graduado y cansado ya de recorrer partes de Europa en su vieja bicicleta, Jürgen se embarcó en Lisboa con destino a Río de Janeiro, atravesó Brasil, luego Bolivia y por fin, como un personaje de Aguinis, recaló en la Universidad de San Marcos, más precisamente en la vivienda universitaria. 


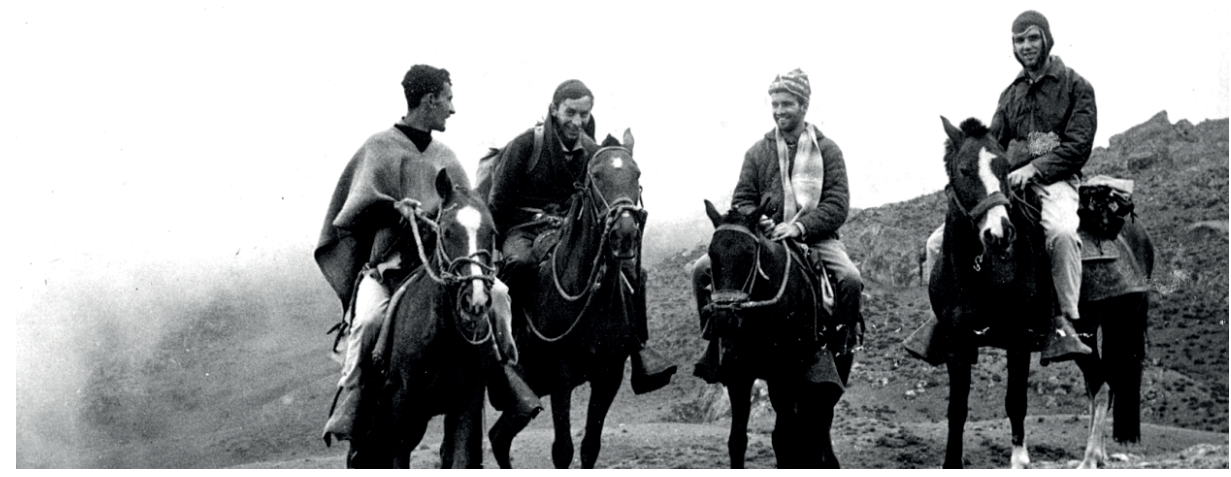

Leonidas Zevallos, Jürgen Golte, Carlos Iván Degregori y Jaime Urrutia en la puna de la comunidad de Pacaraos. Foto: Colección personal de la autora.

El Instituto de Etnología, que funcionaba en ese mismo espacio, atravesaba su mejor momento. Y no es solo la nostalgia la que habla hoy a través de mí. Estaban en la planta de profesores Luis E. Valcárcel, José Matos Mar, José María Arguedas, Jorge Muelle y Alberto Escobar, y a ellos se sumaban profesores extranjeros como Maurice Godelier, Henri Favre y John Murra, para mencionar solo algunos.

Este naturalmente no fue su último viaje, ya que siempre mantuvo un ir y venir entre Alemania y el Perú. Así, por ejemplo, fue a doctorarse de vuelta a Europa para luego volver a los Andes y ser profesor en la Universidad San Cristóbal de Huamanga en Ayacucho, además de, poco a poco, recorrer los destinos más diversos del mundo y del Perú, sintiéndose siempre como un viajero que se compenetraba y conocía los lugares en un plano más profundo que un turista promedio.

Mantuvo una vida académica entre el Perú y Alemania, siempre enseñando, escribiendo, investigando o asesorando investigaciones de sus alumnas y alumnos. Él era alguien que compenetraba su vida personal con sus investigaciones y procesos académicos. Vivir de niña en su casa, en la que desfilaban estudiantes de ambos continentes camino a su trabajo de campo, buscando asesorías de tesis o asistiendo a clases era, sin duda, emocionante. Alrededor de él se congregaban las personas más diversas y se generaba una especie de espacio de aprendizaje. Yo había naturalizado que así era una vida normal, una casa llena de hermanos, hermanas, primos, primas, tíos, tías, amigos, estudiantes y colegas. Era como una gran y extensa situación familiar.

Después de su partida me di cuenta de que no solo yo me sentía así con respecto a la vida a su alrededor, sino también muchas y muchos de sus estu- 
diantes, que luego fueron sus colegas. Muchas personas se comunicaron conmigo expresando su aprecio y sus anécdotas junto a él. Me enteré de que incluso muchas personas veían en él una suerte de figura paterna. Esto no me extranó, debido, por ejemplo, a la manera en la que él se preparaba para sus clases que daba en nuestra sala. Aparte de preparar lo académico, se ponía temprano a preparar sus clásicos queques. Al momento de querer comérmelos antes de sus clases, decía: «iNo, esos son para mis alumnitos!».

Recuerdo claramente cómo olían los famosos «kuchen» para sus clases. La casa en la Calera en la que vivíamos contaba con una arquitectura particular en el primer piso. Todos los espacios estaban conformados como una especie de corredor continuo, con un tragaluz al centro. Esto hacía que al sentarse una en la cocina — donde también comíamos y llevábamos largas, divertidas y profundas sobremesas- pudieses escuchar la sesión que Jürgen y sus estudiantes de pre y posgrado llevaban a cabo con café y queque en la sala.

La clase fluía como una entretenida e hipnotizante conversación que cautivaba a las y los presentes a quedarse largas horas a profundizar aún más en el tema del día. Anécdotas y vivencias se entremezclaban con análisis de textos y discusiones con temáticas de tesis, además de siempre recurrir al humor como parte de las largas conversaciones. El humor que manejaba él era particular y muy bien sintonizado con su directa sinceridad, que bordeaba límites muchas veces impactantes, pero creo que hacían cualquier debate mucho más interesante.

Otro aspecto que convertía clases y conversaciones con él en algo muy cercano y familiar era su manera de narrar. En las clases que lograba escuchar a veces, me transportaba mentalmente a cuando él nos contaba cuentos de pequeños. Eran similarmente hipnotizantes. Las historias de los moches, los cuentos rusos, las fábulas alemanas, las leyendas de sus viajes, etc., confluían con su grave voz para llevarnos al mundo de los sueños con bastante información que procesar. Ya que muchas veces viajaba, y en ese tiempo no había internet ni WhatsApp, recuerdo con mucho cariño que él grababa unos cassettes que siempre comenzaban así: «Hola, Melissita, soy tu papá. Te voy a contar un cuento», y luego, quizás imitando los cassettes de narraciones, hacía sonar un charango algo desafinado.

La facultad de narrar con tanta elocuencia y entender la ilación de narraciones — como solía hacerlo en sus análisis iconográficos — estaba ligada a su afición por leer. No solo devoró muchísimos libros de ciencias sociales, sino también miles de libros de ciencia ficción: simplemente era algo que lo apasionaba.

En un video homenajeando la vida de Carlos Iván Degregori, el propio Jürgen dijo lo siguiente: 
A lo largo de todos esos años, casi cinco décadas, hemos mirado mutuamente qué hacía el otro. Hemos conversado sobre esto y no solamente sobre el trabajo, sino sobre aficiones comunes que teníamos. Es decir, a los dos nos gustaba por ejemplo la literatura y conversábamos mucho sobre novelas en especial. Los dos teníamos una afición por las novelas de ciencia ficción y aunque parezca un poquito «al lado», siempre conversábamos sobre la relación entre ciencia ficción y las sociedades en las que uno vivía; y las características de las sociedades que se convertían en temáticas de los que escribían una novela de ciencia ficción.

Recuerdo haber ido a su pequeño departamento en la Leibnizstrasse en Berlín, que también era un espacio que siempre ponía a disposición de quien lo necesitara, y un día abrir una alacena en búsqueda de algo de comer. No encontré nada que satisficiera mi hambre, pero se desencadenó una avalancha de libros de ciencia ficción. Sabía que leía varios y que también en casa había una buena cantidad de libros similares, pero esto me sorprendió. La curiosidad suya no se saciaba con la realidad, sino que buscaba investigar también en los universos de las novelas de planetas lejanos. La realidad le resultaba especialmente emocionante cuando se asemejaba a la ciencia ficción. Como cuando, por ejemplo, analizaba los frisos mochicas y comparaba las estrellas ahí retratadas con composiciones estelares de esos años en simuladores en internet. Coincidían con tiempos de cosecha de los años en los que estaban datados. La emoción que le generó ese momento - que pude observar- fue única. Parecía que su oficina en casa se había convertido en alguna base rusa, quizás celebrando la salida de órbita de su cosmonauta Valentina Tereshkova o de Yuri Gagarin. Su vida fue tan emocionante que bordeaba muchas veces los límites de la ficción.

Cuando partió sentí un gran vacío, que sé que es compartido con todos quienes lo extrañan. En este escrito no pretendo cubrir todos los ámbitos de su vida académica ni de su biografía, pero sí contar pequeños momentos de su recorrido por esta tierra. Retratar un poco más la calidad de persona que fue Jürgen Golte.

Su carácter e ímpetu científico marcaron positivamente la vida de mucha gente. De algún modo las conversaciones gratas y los debates argumentativos han pasado al ámbito de los libros, y desde ellos podremos seguir conversando con él, leyendo y pensando. Yo lo imagino surcando los caminos a través del mundo de arriba y el mundo de abajo en un barco de totora con Quismique, resolviendo todas las dudas pendientes. Encontrándose de nuevo con aquellos seres amados que partieron antes. A nosotros, aquí en el mundo de los vivos, nos queda la misión de seguir leyéndolo y recordándolo. Seguir investigando para conversar, dialogar y desarrollar con el conocimiento que creó. 


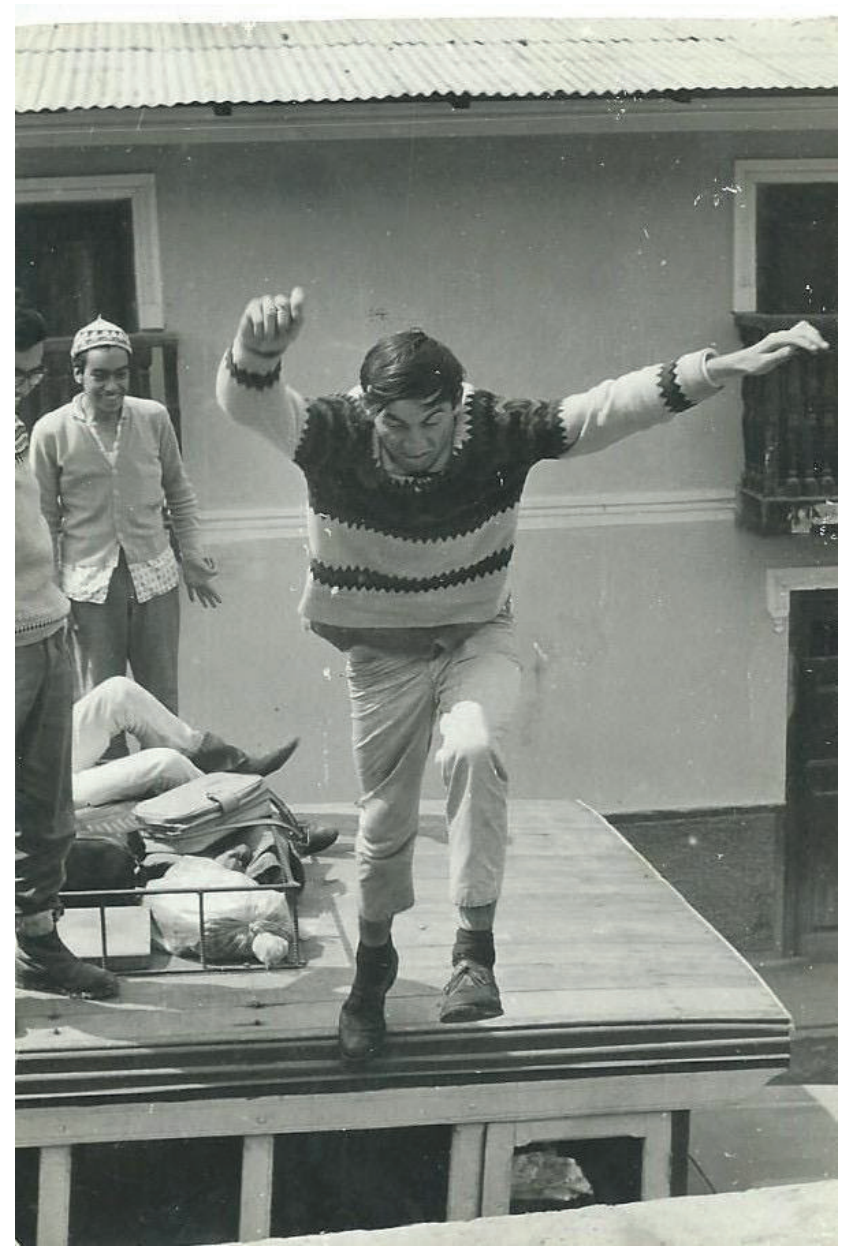

Jürgen Golte saltando desde el techo de un «camión mixto» en un mercado del pueblo de Acos. Atrás, Modesto Gálvez observa. Foto: Colección personal de la autora. 


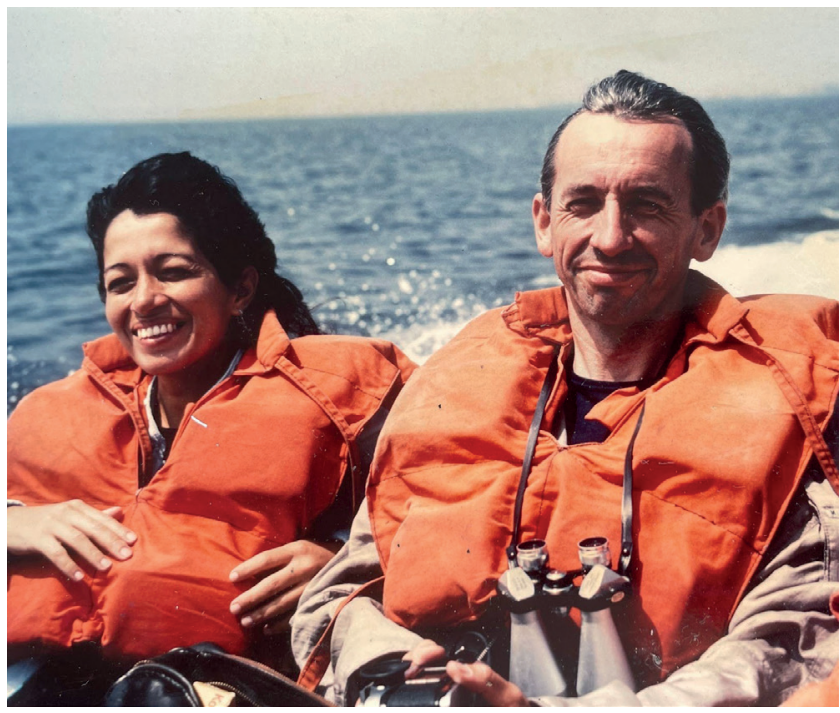

Antropóloga Norma Adams Alegre y Jürgen Golte. Foto: Colección personal de la autora.

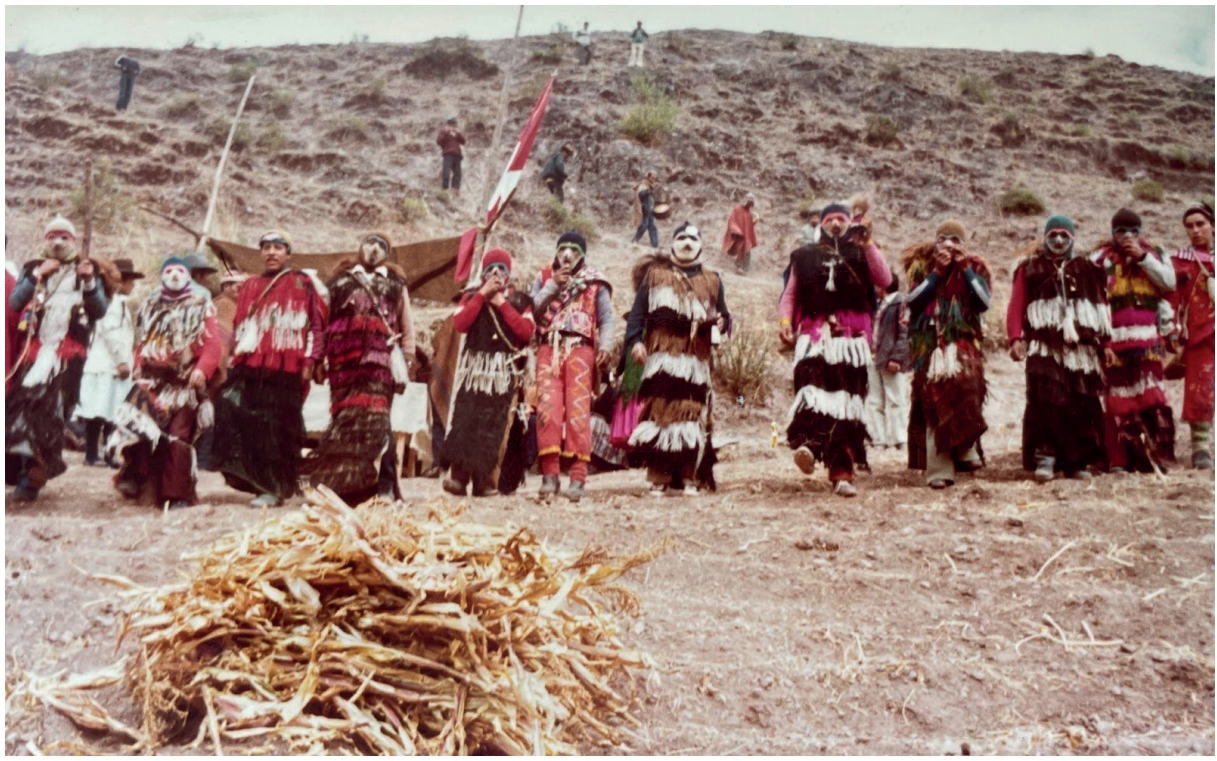

Ukukus. Foto: Jürgen Golte. Colección personal de la autora. 


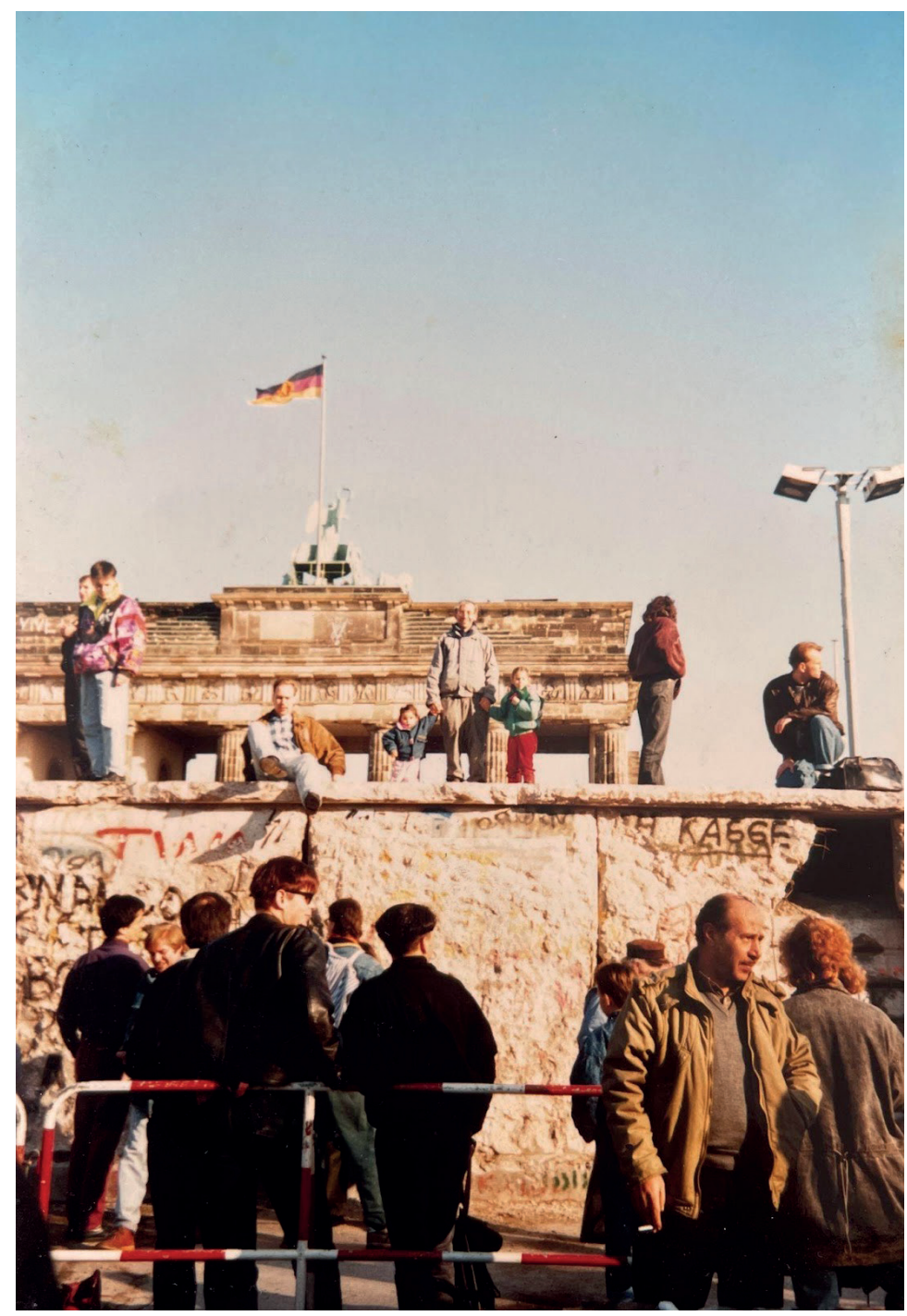

Caída del muro de Berlín. Foto: Colección personal de la autora. 